\title{
SIDE EFFECTS PROFILE OF ANTIPLATELET MEDICATION IN PATIENTS WITH CORONARY HEART DISEASE AT BHAYANGKARA HOSPITAL BALI-INDONESIA
}

\author{
Anak Agung Indah Astrijayanti ${ }^{1}$, Ida Ayu Manik Partha Sutema ${ }^{1}$, Ni Putu Wulanda Evayanti ${ }^{2}$, \\ Ni Ketut Tria Purnamisari ${ }^{2}$, Made Krisna Adi Jaya ${ }^{2 *}$ \\ ${ }^{1}$ Clinical Pharmacy Department, Universitas Bali Internasional, Bali-Indonesia \\ ${ }^{2}$ Department of Pharmacy, Faculty of Math and Science, Udayana University, Bali, Indonesia \\ Corresponding author email: krisnaadijaya@unud.ac.id
}

\begin{abstract}
Introduction: Coronary heart disease (CHD) is a disorder of heart function due to a lack of blood in the heart muscle due to narrowing of the coronary arteries. Antiplatelet in patients with CHD is a therapy that must be obtained by patients throughout their lives to prevent recurrent attacks and deaths from CHD. In the Province of Bali, especially in Denpasar, there is a lack of information about the type of side effects that occur on antiplatelet medication, so it is necessary to do a related study. Objective: The aim of this study is to identify the type of side effects that occur on antiplatelet medication in patients with CHD. Methods: A cross-sectional study involving 97 patients was done by observed the CHD patients treated with antiplatelet medication. Side effects were evaluate using Naranjo Algorithm. Patients were divided into three groups, including a low dose aspirin user group, clopidogrel user group, and aspirinclopidogrel combination user group. Results: Antiplatelet side effects that occur in patients include headache $(2.06 \%)$, diarrhea $(1.03 \%)$, cyanosis $(1.03 \%)$, gastrointestinal bleeding $(8.25 \%)$, heartburn $(11.34 \%)$, and nausea $(6.19 \%)$. These side effects only occurred in $31.96 \%$ of the total subjects. The incidence of aspirin side effects was significantly greater than clopidogrel as well as aspirin-clopidogrel in combination $(p<0.05)$. Conclusion: Patients with CHD who use antiplatelet agents in the long term to be more aware of the potential side effects that will occur, especially heartburn in chronic low-dose aspirin users.
\end{abstract}

Keywords: Coronary Heart Disease, Side Effects, Antiplatelet, Aspirin, Clopidogrel

\section{INTRODUCTION}

Coronary heart disease (CHD) is a disorder of cardiac function caused by heart muscle deficiency of blood due to the narrowing of coronary arteries. Clinically, characterized by chest pain or chest felt depressed while doing a heavy kind of activity, a quick walk, when walk on a flat road or have a far walk. This narrowing of coronary arteries is commonly called arteriosclerosis, and one form of arteriosclerosis is a narrowing due to saturated fats, called atherosclerosis ${ }^{[1]}$. More than $80 \%$ of the deaths from cardiovascular disease happened in low-and middle-income countries and counting under the age of 60 years, which is in productive age. Coronary heart disease is now the leading cause of death in the world, both in men and women ${ }^{[2]}$.

Antiplatelet is the primary therapy used to prevent thrombosis in patients with cardiovascular disease (CVD). One of the most widely used antiplatelet is the low dose of aspirin and clopidogrel. Antiplatelet is advised to be given for a long period through CHD patients. However, the use of 
antiplatelet agents in a long time potentially raises the drug-related problems, so we have to point the side effects such as gastrointestinal irritation and bleeding and allergies. A case-crossover study involved 10,905 patients with large hemorrhagic complications and prescription low dose aspirin (300 mg/day) from $2000-2008$. The use of low-dose aspirin increases the risk of major piles 1.33 fold $(95 \% \mathrm{CI}=$ $1.13-1.55, \mathrm{p}=0.001$ ) and significance found in 4.453 of non-hypertensive and nondiabetic subjects (adjusted odds ratio $=1.88$; 95\%CI: $1.21-2.91)^{[3]}$.

At present, in Bali, especially in Denpasar city, there is no data related to the incidence of antiplatelet medication side effects. So, further research is needed to provide an overview for health practitioners in this regard, making it easier to take action if unexpected side effects occur in patients using chronic antiplatelet agents.

\section{METHODS}

\section{Population and Subjects of Study}

This study was a cross-sectional. The population was an outpatient heart disease patient in Bhayangkara hospital, BaliIndonesia, who receives antiplatelet medication. The subjects criteria defined in this study were patients diagnosed with CHD, willing to participate in this research by filling the approval consents, have used antiplatelet agents for at least a month, and have proper therapeutic compliance. Patients who have a $<80 \%$ adherence rate assessed by the pill count method will not be included as subjects in this study.

\section{Clinical Judgement}

Subjects characteristics such as age, gender, Body Mass Index (BMI), smoking history, disease comorbidity, and other drug therapies were determined as baseline characteristics. The data collection method uses the direct measurement technique using the Naranjo algorithm as a potential side-effect measuring tool. Patients who have received antiplatelet agents for at least one month were evaluated while performing monthly controls. Data collection is done by directly observing the complaints of patients during drug use. Complaints suspected to originate from antiplatelet agents will be assessed using the Naranjo algorithm. Naranjo scores $>4$ with "probable" and "definitive" categories, which will be recorded as specific side effects of the use of the antiplatelet agent ${ }^{[4]}$.

Patient compliance was assessed using pill count. Patients who will come for monthly control were contacted to bring all the remaining medication at their home. In the hospital, the subject will be assessed for compliance from the amount of the remaining drug that was still carried. Patients were categorized as compliant if the amount of the remaining drug was not more than $20 \%$ of the total amount of the drug received. The history of the total patient drug previously received can be accessed through its electronic medical record.

\section{Statistical analysis}

Statistical analysis was conducted by non-parametric analysis. Baseline characteristics between study groups were analyzed using the Kruskal Wallis test. Antiplatelet adverse event events data were presented with numerical data packaged in a table, where adverse event events were grouped according to study groups. A comparison of the incidence of side effects of antiplatelet agents between groups was tested using Kruskal Wallis. All tests were facilitated with IBM 21 SPSS software.

\section{RESULTS}

This study had observed 97 patients according to the study criteria. The study subjects were divided into three groups based on the therapy obtained by 42 patients in the aspirin group, 42 patients in the clopidogrel group, and 13 patients in the combination group of aspirin and clopidogrel. 
Table 1. Baseline Characteristics of Study Subjects

\begin{tabular}{|c|c|c|c|c|}
\hline Characteristics & $\begin{array}{l}\text { Aspirin } \\
(n=42)\end{array}$ & $\begin{array}{l}\text { Clopidogrel } \\
\qquad(n=42)\end{array}$ & $\begin{array}{c}\text { Aspirin and Clopidogrel } \\
\text { Combination } \\
(n=13)\end{array}$ & p value \\
\hline Age (year) & $63.57 \pm 7.95$ & $61.83+9.08$ & $63.77 \pm 7.93$ & 0.363 \\
\hline \multicolumn{5}{|l|}{ Gender [n(\%)] } \\
\hline Female & $9(21.43 \%)$ & $12(28.57 \%)$ & $4(30.77 \%)$ & \multirow{2}{*}{0.688} \\
\hline Male & $33(78.57 \%)$ & $30(71.43 \%)$ & $9(69.23 \%)$ & \\
\hline BMI $\left(\mathrm{kg} / \mathrm{m}^{2}\right)$ & $25.07 \pm 3.05$ & $24.91 \pm 2.86$ & $23.97 \pm 2.68$ & 0.119 \\
\hline \multicolumn{5}{|l|}{ Smoking History [n(\%)] } \\
\hline No & $17(40.48 \%)$ & $16(38.1 \%)$ & $5(38.46 \%)$ & \multirow{3}{*}{0.849} \\
\hline Yes & $5(11.91 \%)$ & $4(9.52 \%)$ & $0(0 \%)$ & \\
\hline Stopped & $20(47.62 \%)$ & $22(52.38 \%)$ & $8(61.53 \%)$ & \\
\hline \multicolumn{5}{|c|}{ Diseases Comorbidity [n(\%)] } \\
\hline Diabetes & $4(9.52 \%)$ & $3(7.14 \%)$ & $0(0 \%)$ & \multirow{10}{*}{$0.012 *$} \\
\hline Hypertension & $5(11.91 \%)$ & $8(19.05 \%)$ & $1(7.69 \%)$ & \\
\hline Parkinson & $2(4.76 \%)$ & $0(0 \%)$ & $0(0 \%)$ & \\
\hline Asthma & $2(4.76 \%)$ & $2(4.76 \%)$ & $0(0 \%)$ & \\
\hline Meningitis & $1(2.38 \%)$ & $0(0 \%)$ & $0(0 \%)$ & \\
\hline Prostat & $1(2.38 \%)$ & $0(0 \%)$ & $0(0 \%)$ & \\
\hline Chronic Kidney Disease & $2(4.76 \%)$ & $1(2.38 \%)$ & $0(0 \%)$ & \\
\hline Post Stroke & $1(2.38 \%)$ & $0(0 \%)$ & $0(0 \%)$ & \\
\hline Gastritis & $4(9.52 \%)$ & $1(2.38 \%)$ & $0(0 \%)$ & \\
\hline HHD & $0(0 \%)$ & $1(2.38 \%)$ & $0(0 \%)$ & \\
\hline \multicolumn{5}{|c|}{ Other Ongoing Medication [n(\%)] } \\
\hline Antihypertension & $38(90.48 \%)$ & $40(95.24 \%)$ & $13(100 \%)$ & 0.408 \\
\hline Antidiabetes & $4(9.52 \%)$ & $1(2.38 \%)$ & $0(0 \%)$ & 0.226 \\
\hline Antidislipidemia & $15(35.71 \%)$ & $20(47.62 \%)$ & $7(53.85 \%)$ & 0.392 \\
\hline Vasodilator & $5(11.9 \%)$ & $5(11.9 \%)$ & $0(0 \%)$ & 0.426 \\
\hline
\end{tabular}

Table information: $\mathrm{n}=$ subject; $\mathrm{BMI}=$ Body Mass Index; $\mathrm{DM}=$ Diabetes Mellitus; HHD= Hypertensive Heart Disease

\section{Baseline Subject Characteristics}

Table 1 shows the characteristics of the subjects in the study. The results of this characteristic analysis show that all characteristic parameters except for disease comorbidity are not significantly different. So that it can be stated that almost all baselines between test groups have the same characteristics. The concomitant disease was one of the characteristics that were difficult to be uniform, but this parameter was considered not to affect outcomes in this study.

\section{Side Effects Profile of Antiplatelet Agents}

Based on direct observations showed in Table 2, overall side effects that appeared in 97 patients using antiplatelet were headache $(2.06 \%)$, diarrhea $(1.03 \%)$, cyanosis $(1.03 \%)$, GI bleeding $(8.25 \%)$, heartburn
(11.34\%), and nausea (6.19\%). These side effects only occurred in $31.96 \%$ of the total subjects observed. In the aspirin group, showed the most types of side effects occur compare to other groups. Side effects that need to be focused are heartburn, GI bleeding, and nausea. These side effects were the highest incidence in this study.

The results of statistical analysis showed that there was a significant difference in the incidence rate of adverse events between the three research groups $(\mathrm{p}<0.05)$ showed in Table 3. The pooled analysis showed that the long-term aspirin alone group tended to experience side effects more frequently than the other groups. A side effect that needs attention from the use of aspirin is heartburn. Heartburn is one of the symptoms that indicates that the aggressive factor in the stomach is more dominant than the defensive factor. In addition to reducing the 
Table 2. Frequency Distribution of Side Effects

\begin{tabular}{llcc}
\hline Side Effect & $\begin{array}{c}\text { Aspirin } \\
(\mathbf{n = 4 2})\end{array}$ & $\begin{array}{c}\text { Study Groups } \\
\text { Clopidogrel } \\
(\mathbf{n = 4 2 )}\end{array}$ & $\begin{array}{c}\text { Aspirin and Clopidogrel } \\
\text { Combination } \\
(\mathbf{n = 1 3})\end{array}$ \\
\hline Headache & $0(0 \%)$ & $2(4.76 \%)$ & $0(0 \%)$ \\
Diarrhea & $1(2.38 \%)$ & $0(0 \%)$ & $0(0 \%)$ \\
Cyanosis & $0(0 \%)$ & $1(2.38 \%)$ & $0(0 \%)$ \\
GI bleeding & $6(14.29 \%)$ & $0(0 \%)$ & $2(15.38 \%)$ \\
Heartburn & $10(23.81 \%)$ & $0(0 \%)$ & $1(7.70 \%)$ \\
Nausea & $6(14.29 \%)$ & $0(0 \%)$ & $0(0 \%)$ \\
\hline
\end{tabular}

Table information: $n=$ subjects

Table 3. Side Effect Comparison of the Antiplatelet Agent in the Study Groups

\begin{tabular}{lcccc}
\hline Side Effect & $\begin{array}{c}\text { Aspirin } \\
(\mathbf{n = 4 2})\end{array}$ & $\begin{array}{c}\text { Clopidogrel } \\
(\mathbf{n = 4 2})\end{array}$ & $\begin{array}{c}\text { Aspirin and Clopidogrel } \\
\text { Combination } \\
(\mathbf{n = 1 3})\end{array}$ & p Value \\
\hline Not occur & $19(45.24 \%)$ & $37(88.09 \%)$ & $10(76.92 \%)$ & $0.001 *$ \\
Occur & $23(54.76 \%)$ & $5(11.90 \%)$ & $3(23.07 \%)$ & \\
\hline
\end{tabular}

Table information: $\mathrm{n}=$ subjects

quality of life of patients, untreated heartburn can lead to more serious gastrointestinal conditions such as gastroesophageal reflux disease (GERD) and peptic ulcer disease (PUD).

Clopidogrel alone and aspirinclopidogrel combination were seen to have a lower incidence of side effects. This does not suggest that this group is always safer than the aspirin group alone. The use of antiplatelet agents, in essence, still requires monitoring by pharmacists in particular, so that patient safety can always be maintained.

\section{DISCUSSION}

In this study, the greatest number of antiplatelet side effects occurred in the aspirin group. In an observational study that has been done before, showed upper gastrointestinal (GI) discomfort was found significantly lower for clopidogrel compare to aspirin (dyspepsia $0.97 \%$ compared to $1.22 \%$ $\mathrm{p}<0.05$; severe GI bleeding $0.52 \%$ versus $0.72 \% ; \mathrm{p}<0.05)^{[5]}$. That study shows the similarities found in this study. Clopidogrel was found safer from side effects than aspirin in this study. When we look deeper, the total incidence of antiplatelet agent side effects in this study tends to be low $(<50 \%)$. Approximately $68 \%$ of the subjects have not shown signs of side effects from the use of antiplatelet agents. This could be due to a lack of observation duration or due to individual factors that are well tolerated against these antiplatelet agents ${ }^{[5]}$.

Heartburn is one of the dominant side effects that appear in subjects who use aspirin. Based on the pharmacokinetic profile, the oral bioavailability of the usual aspirin tablets is $40 \%$ to $50 \%$ in a variety of doses. Although the acetylation is rapidly from the circulation, the platelet inhibitory effect will persist during the lifetime platelet due to an irreversible aspirin invocation of platelet Cyclooxygenase $1(\mathrm{COX}-1)^{[6]}$. This condition causes side effects of heartburn due to decreased mucus production in the gastrointestinal tract resulting in nonselective inhibition of COX enzymes, especially COX- 1 .

Clopidogrel is antiplatelet that works by inhibiting adenosine diphosphate (ADP), which will inhibit platelet aggregation pathways. The pharmacokinetic profile of clopidogrel showed absorption is higher than $50 \%$ and rapidly absorbed after oral administration. Clopidogrel underwent rapid hydrolysis to a derivative of carboxylic acid. The half-life of the major circulating metabolite is 8 hours, with $50 \%$ excreted in the urine and $46 \%{ }^{[7]}$. In this study, clopidogrel does not cause many side effects, 
but further research is needed to evaluate the side effects of drugs with more subjects and longer observation duration.

This study has limitations in the form of not evaluating the effectiveness of antiplatelet therapy. Because the incidence of low side effects is not always directly proportional to the high effectiveness. Aspirin may cause more side effects than the other groups in this study, but the effectiveness of aspirin may be better than other antiplatelet agents. More holistic studies are recommended to continue until entering the evaluation of effectiveness and cost aspects.

Based on this study, the recommendation that can be informed is that aspirin can still be given to patients who need antiplatelet agents, especially in CHD patients. The dominant side effects of heartburn appearing on aspirin can be overcome by increasing the defensive factor or decreasing the aggressive factor. Defensive factors can be increased by prostaglandin or cytoprotective analog drugs, while aggressive factors can be reduced by using proton pump inhibitor (PPI) drugs, $\mathrm{H} 2$ Antagonist Receptor (H2RA), and gastric $\mathrm{pH}$ enhancing agents such as antacids ${ }^{[7]}$.

\section{CONCLUSION}

Antiplatelet side effects that occur in patients include headache, diarrhea, cyanosis, GI bleeding, heartburn, and nausea. Subjects who use aspirin suffer more side effects. The most dominant side effect found is heartburn.

\section{CONFLICT OF INTEREST}

This paper was written independently. All authors disclose no financial or personal relationships with other people or organizations that could inappropriately influence the work.

\section{ACKNOWLEDGMENTS}

We thank lecturers and staff in the Department of Pharmacy, Universitas Bali
Internasional, and Department of Pharmacy, Faculty of Math and Science, Udayana University, Bali Indonesia, for the support in the implementation of research.

\section{REFERENCES}

1 Jaya, M.K.A and Swastini, D.A. A Case Control Study Of Risk Factors Associated With Atherosclerotic Cardiovascular Disease (ASCVD) On Patients In Bali Island. Int $\mathbf{J}$ of Phar Res. 2020. 12(1) : 2802-2807.

2 Rilantono, L.I. Penyakit Kardiovaskular (PKV), Pertama cetakan V. Jakarta: Badan Penerbit Fakultas Kedokteran Universitas Indonesia; 2018.

3 Wu IC., Lin MY., Yu FJ., et al. A ShortTerm Effect of Low-Dose Aspirin on Major Hemorrhagic Risks in Primary Prevention: A Case-Crossover Design. 2014. 9(5) : 1-10.

4 Supardi, S. dan Surahman. Metodologi Penelitian untuk Mahasiswa Farmasi. Jakarta: CV. Trans Info Media; 2014.

5 Yasuda H., Yasumasa M., Yoshinori S., et al. Treatment and prevention of gastrointestinal bleeding in patients receiving antiplatelet therapy. World J Crit Care Med. 2015. 4(1): 40-46.

6 Eikelboom JW., Hirsh J., Spencer FA., et al. Antiplatelet Drugs. Antithrombotic Therapy and Prevention of Thrombosis, 9th ed: American College of Chest Physicians Evidence-Based Clinical Practice Guidelines. 2012. 141 (2) : e89Se119S.

7 Kumar P, K., Vijayakumar, S., Reddy Y, N. Clopidogrel - An Overview. International Journal of Pharmacology Research. 2013. 3(1) : 1-7. 